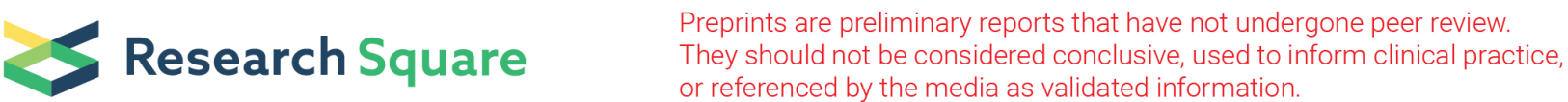

\section{Anastomotic Leakage Following Resection of the Esophagus - Introduction of an Endoscopic Scoring System}

Jeannine Bachmann ( $\sim$ jeannine.bachmann@tum.de)

Technical University of Munich: Technische Universitat Munchen https://orcid.org/0000-0001-68337302

\section{Marcus Feith}

Technical University Munich: Technische Universitat Munchen

Christoph Schlag

Technical University of Munich: Technische Universitat Munchen

Mohamed Abdelhafez

Technical University Munich: Technische Universitat Munchen

Marc Martignoni

Technical University of Munich: Technische Universitat Munchen

Helmut Friess

Technical University of Munich: Technische Universitat Munchen

\section{Research Article}

Keywords: anastomotic leakage, endoscopic scoring system, endoluminal vacuum therapy

Posted Date: November 3rd, 2021

DOl: https://doi.org/10.21203/rs.3.rs-111846/v2

License: (c) (1) This work is licensed under a Creative Commons Attribution 4.0 International License.

Read Full License 


\section{Abstract}

\section{Background}

Malignant tumors of the esophagus are the sixth leading cause of cancer-related deaths worldwide. Postoperative leakage of the esophago-gastrostomy leads to mediastinal sepsis, which is still associated with a high morbidity and mortality rate.

The aim of this study was to describe the endoscopic view of the different severity grades of an anastomotic leakage.

\section{Methods}

Patients

Between June 2016 and September 2018, 144 patients were operated upon in the Department of Surgery, University of Munich, Germany.

Among these patients, 34 (23.6\%) presented with a leakage of the anastomosis.

\section{Endoscopy}

In this retrospective analysis the focus is to describe different patterns of leakage of the anastomosis.

\section{Results}

We studied 34 patients in whom post-esophagectomy leakage of the anastomosis was detected and treated with an endoluminal vacuum sponge system.

The leakage healed in 26 of 29 patients (success rate $89.7 \%$ ).

With increasing severity of leakage, the treatment time and the in-hospital mortality correspondingly increased. Furthermore, the incidence of development of a fistula to the tracheobronchial system increased with higher grades of leakage.

\section{Conclusions}

Exact descriptions of leakage are necessary to compare the cases and to prove post-treatment improvement. This is, to our knowledge, the first publication to present a leakage grading score in patients after esophagectomy including reconstruction with a gastric tube.

This new grading system needs to be tested in further analyses, with special focus on prospective analysis.

\section{Introduction}


Malignant tumors of the esophagus are the sixth leading cause of cancer-related deaths worldwide [1, 2]. The operative procedure in patients with cancer of the esophagus and the esophagogastric junction - a right abdominothoracic esophagectomy with intrathoracic anastomosis and two field lymphadenectomy - is still demanding due to a high morbidity and mortality rate. Postoperative leakage of the esophagogastrostomy leads to mediastinal sepsis, which is still associated with a high morbidity and mortality rate; morbidity rates of up to $73 \%$ are reported $[3,4]$. Furthermore, a hospital mortality of up to $9.6 \%$ is reported $[3,5]$. A recent meta-analysis, which included the data of 11368 patients with esophageal cancer, revealed a significant correlation of postoperative anastomotic leakage with a decreased 5-year survival as well as with a decreased 5-year disease-free survival [6]. One major factor contributing to morbidity as well as mortality is leakage of the anastomosis, which is reported in up to $23 \%$ of cases $[3,5,7,8]$. In addition, anastomotic leakage after resection of the esophagus or the esophagogastric junction has a significant negative effect on long-term survival $[5,6]$.

However, what exactly can be termed a leakage of the esophago-gastric anastomosis? There is still no clear definition; especially, no gradation is available. To compare different patient collectives and to define the best treatment standards for different degrees of anastomotic leakage, a pragmatic and clear definition is needed.

Furthermore, the best method to detect a leakage is still under discussion [9].

Additionally, the appropriate treatment of an anastomotic leakage following esophagectomy is still being debated. Vacuum-assisted closure is a method first described in 2008 by Wedemeyer et al [10]. Several reports have investigated the treatment of anastomotic leakages using this system; success rates up to $88 \%$ are reported $[8,11,12]$.

The aim of this study was to define a leakage of the esophago-gastric anastomosis by using endoscopy and to describe the endoscopic view of the different severity grades of an anastomotic leakage.

\section{Patients And Methods}

\section{Patients}

Between June 2016 and September 2018, 144 patients were operated upon in the Department of Surgery, University of Munich, Germany. Among these patients, 34 (23.6\%) presented with a leakage of the anastomosis; a vacuum-assisted closure system was used to treat the leakage in these patients. Eight patients had squamous cell cancer of the esophagus, 25 had adenocarcinoma of the distal esophagus, and one had achalasia. In 26 patients (76.5\%), neoadjuvant treatment was used (14 patients received only chemotherapy before operation, while 12 received combined radio-chemotherapy). Every patient gave informed consent to publish data in an anonymus matter.

\section{Operative procedure}


The first operative step is the incision of the upper epigastrium for mobilization of the stomach, followed by the formation of a gastric tube along the greater curvature. Lymphadenectomy along the celiac axis and parapancreatic region is performed. Then, abdominotransthoracic en bloc esophagectomy is done through a right transthoracic approach, including lymphadenectomy in the upper mediastinum. The reconstruction of the intestinal passage is finished with an esophagogastrostomy using the circular stapling method [13]. After esophagectomy, endoscopy was performed in cases where signs indicating possible leakage, such as fever or a change in the drainage fluid, were noted.

\section{Endoscopy}

In this study, the endoscopic view in the postoperative course after esophagectomy and reconstruction with gastric tube is presented. The focus is to describe different patterns of leakage of the anastomosis. The analysis is retrospective.

First, the anastomosis is described clockwise: the 12 o'clock position on the endoscopic view is the localized ventral (retrosternal) aspect of the anastomosis; at the 3 o'clock position, the inverted blind stump is located; and at the 6 o'clock position, the dorsal part of the anastomosis is located. Table 1 provides an overview of the examined data.

Table 1

endoscopic view of the anastomosis and the tubular stomach

\begin{tabular}{|c|c|}
\hline & appearance \\
\hline \multirow[t]{4}{*}{ leakage } & 12-3 o'clock quadrant \\
\hline & 3-6 o'clock quadrant \\
\hline & 6-9 o'clock quadrant \\
\hline & 9-12 o'clock quadrant \\
\hline \multirow[t]{3}{*}{ tubular stomach } & rosy \\
\hline & necrotic mucosa \\
\hline & necrotic wall \\
\hline \multirow[t]{2}{*}{ dehiscence } & without cavity \\
\hline & with cavity \\
\hline \multirow[t]{4}{*}{ anastomosis } & rosy \\
\hline & $\begin{array}{l}\text { partial necrotic }<1 / 4 \\
\text { circumference }\end{array}$ \\
\hline & necrotic $>1 / 4$ circumference \\
\hline & necrotic whole circumference \\
\hline
\end{tabular}


If dehiscence of the anastomosis is detected, its location and size are both documented. If a cavity is present, its presence is noted and its dimensions, including depth, are mentioned. The mucosa and the gastric tube wall are checked for signs of perfusion or necrosis. If there is necrotic and / or fibrotic tissue in the anastomotic region and dehiscence of less than a quadrant of the circumference is detected, a grade 1 leakage is diagnosed. This grade is furthermore separated into grade $1 \mathrm{a}$ and $1 \mathrm{~b}$, respectively. Grade $1 \mathrm{a}$ is diagnosed if anastomosis is present without a cavity; in case of a leakage less than a quarter of the circumference with a cavity, grade $1 \mathrm{~b}$ is diagnosed.

Grade 2 is diagnosed if dehiscence of the anastomosis exceeds a quarter of the circumference. If necrosis is seen in the mucosa of the gastric tube, grade 3 is diagnosed, whereas grade 4 is diagnosed if necrosis of the tubular stomach is detected. Using this exact description and localization of the dehiscence, it is possible to compare the results of the following endoscopic examinations.

In our analysis, the different grades lead to different treatment options. In patients with leakage of grade $1 \mathrm{a}$ and $1 \mathrm{~b}$, the sponge was placed into the lumen of the esophagus and tubular stomach, respectively. In patients with grade 2 leakage, the vacuum system was placed into the cavity after wound debridement. In patients with grade 3 leakage, the sponge was placed into the lumen of the tubular stomach. In patients with grade 4, reoperation is mostly considered; if this is not possible due to the patient's condition, an endoluminal vacuum treatment is applied. Figure 1 presents an algorithm that is used to determine where the sponge should be placed: in the lumen of the gastric tube or in the cavity.

Table 2 provides a grading system that takes all the above-mentioned parameters into account to show the severity of the leakage.

Table 2

grade of leakage and endoscopic appearance

\begin{tabular}{|llll|}
\hline grade & dehiscence of anastomosis & cavity & tubular stomach \\
\hline $1 \mathrm{a}$ & $<1 / 4$ of the circumference & no & rosy \\
\hline $1 \mathrm{~b}$ & $<1 / 4$ of the circumference & yes & rosy \\
\hline 2 & $>1 / 4$ of the circumference & yes & rosy \\
\hline 3 & yes / no & yes / no & necrotic mucosa \\
\hline
\end{tabular}

\section{Statistical analysis}

Statistical analysis was performed using SPSS software, version 25 (SPSS Inc., Chicago, IL, USA). Results are displayed in median [with lower and upper quartile]. For testing significant differences between the examined groups, we used Student's t-test and the Mann-Whitney $\mathrm{U}$ test. A significance level $<0.05$ was used. 


\section{Results}

Between June 2016 and August 2018, in the Department of Surgery, University of Munich, 34 patients presented with a leakage of the anastomosis after esophagectomy with reconstruction with a gastric tube, in whom a vacuum-assisted closure system was used. No fistulae were detected on the initial endoscopic examination after operation.

The median day of detection of the leakage was day 6 after the operation (5/9 lower/ upper quartile). During the postoperative course, 5 (14.7\%) patients died. The data of these patients were excluded from further analysis.

To present the different clinical courses of the patients depending on the scoring system, the data are presented for every severity grade in detail.

\section{Grade 1a}

Twelve patients presented with leakage of grade 1a severity. In these, the sponge was placed into the esophageal lumen and tubular stomach and was changed after two to three days. The in-hospital mortality was $8.3 \%$. The median number of days of treatment with the vacuum system was $15(9 / 31$ lower/upper quartile). The clinical success rate was 100\% (11/11). In 8 patients (72.7\%), only the sponge treatment was treatment with regard to the leakage. In 2 patients (18.2\%), after extracting the sponge, a clip was applied. In one patient, a self-expanding stent was used after the sponge treatment; the stent was removed 4 weeks later.

In all cases, an endoscopic check as well as a contrast swallow radiograph was performed to determine treatment success.

\section{Grade 1b}

Ten patients presented with leakage of grade $1 \mathrm{~b}$ severity. In these patients, the sponge was placed into the esophageal lumen and tubular stomach and was changed after two to three days. The in-hospital mortality reached $10 \%$ in grade $1 \mathrm{~b}(1 / 10)$.

The median number of days of treatment was 25 (14/35 lower/upper quartile). The success rate in grade $1 \mathrm{~b}$ was $88.9 \%(8 / 9)$. One patient developed a fistula to the tracheobronchial system. In 4 patients (44.4\%), the leakage healed with the endoluminal sponge treatment; in 2 patients, a self-expanding stent was applied (22.2\%); and in 2 patients, a clip was used to close the leakage after treatment with the endoluminal vacuum system (22.2\%).

\section{Grade 2}

In 8 patients with a dehiscence of the anastomosis $>1 / 4$ circumference with an existing cavity, the sponge was placed into the cavity after the cavity was debrided. One patient $(12.5 \%)$ died within thirty postoperative days. 
The median treatment period was 27 days (18/34 lower/upper quartile). The success rate in grade 2 was $71.4 \%$ (5/7); in 4 patients (57.1\%), the leakage healed with the endoluminal sponge treatment, while in 1 patient, a self-expanding stent was used after extraction the sponge. Two patients developed a fistula to the tracheobronchial system during the postoperative course

\section{Grade 3}

Two patients presented with grade 3 leakage. The vacuum-assisted closure system was placed into the lumen in both patients. During the postoperative course, one of these patients died.

\section{Grade 4}

Two patients were classified as having grade 4 leakage; both were treated with an endoluminal placed vacuum-assisted closure system. One patient died within 30 days postoperatively.

\section{Discussion}

Anastomotic leakage after esophagectomy with reconstruction with a tubular stomach remains a severe complication with a high risk for mortality and morbidity. This is, to our knowledge, the first publication in which the leakage is described with different severity grades as determined based on the endoscopic view.

We studied 34 patients in whom post-esophagectomy leakage of the anastomosis was detected and treated with an endoluminal vacuum sponge system. The overall mortality rate was $14.7 \%(5 / 34)$; the data of these patients were excluded from further analyses. In Table 3 the data are presented with regard to the severity.

Table 3

severity of leakage

\begin{tabular}{|llll|}
\hline grade & $\begin{array}{l}\text { patients } \\
\mathbf{N}\end{array}$ & $\begin{array}{l}\text { periop. mortality } \\
\%(\mathrm{~N})\end{array}$ & $\begin{array}{l}\text { development of fistulae } \\
\%(\mathrm{~N})\end{array}$ \\
\hline $1 \mathrm{a}$ & 12 & $8.3(1)$ & $0(0)$ \\
\hline $1 \mathrm{~b}$ & 10 & $10(1)$ & $10(1)$ \\
\hline 2 & 8 & $12.5(1)$ & $25(2)$ \\
\hline 3 & 2 & n.d. $(\mathrm{N}=1)$ & n.d. $(\mathrm{N}=1)$ \\
\hline 4 & 2 & n.d. $(\mathrm{N}=1)$ & n.d. $(\mathrm{N}=0)$ \\
\hline $\begin{array}{l}\text { with increasing grade of leakage the development of a fistula to the tracheobronchial system was } \\
\text { increasing }\end{array}$ & \\
\hline
\end{tabular}


The leakage healed in 26 of 29 patients (success rate 89.7\%). In 16 (61.5\%) patients, the sponge system alone was successful, while in $6(23.1 \%)$, a self-expanding stent was used after treatment with the sponge. In the remaining 4 (15.4\%) patients, a clip was applied. A contrast swallow proved the success of the treatment in all patients.

Due to a small number of patients in the grade 3 and 4 categories, we compared the following data only in groups $1 \mathrm{a}, 1 \mathrm{~b}$, and 2 . With increasing severity of leakage, the treatment time and the in-hospital mortality correspondingly increased. As the leakage grade increased, the healing success rate decreased: in grade $1 \mathrm{a}$ cases, the success rate was $100 \%$, which reduced to $88.9 \%$ in grade $1 \mathrm{~b}$ and $71.4 \%$ in grade 2 . Furthermore, the incidence of development of a fistula to the tracheobronchial system increased with higher grades of leakage, see Table 4.

Table 4

severity of leakage with duration of treatment

\begin{tabular}{|llll|}
\hline grade & $\begin{array}{l}\text { patients } \\
\mathbf{N}\end{array}$ & $\begin{array}{l}\text { median duration of treatment } \\
\text { (days) }\end{array}$ & $\begin{array}{l}\text { healing of leakage } \\
\%(\mathrm{~N})\end{array}$ \\
\hline $1 \mathrm{a}$ & 11 & $15(9 / 31)$ & $100(11)$ \\
\hline b & 9 & $25(14 / 35)$ & $88.9(8)$ \\
\hline 2 & 7 & $27(18 / 34)$ & $71.4(5)$ \\
\hline 3 & 1 & n.d. $(\mathrm{N}=1)$ & n.d. $(\mathrm{N}=1)$ \\
\hline 4 & 1 & n.d. $(\mathrm{N}=1)$ & $(\mathrm{N}=1)$ \\
\hline
\end{tabular}

\section{Conclusions}

Exact descriptions of leakage are necessary to compare the cases and to prove post-treatment improvement. This is, to our knowledge, the first publication to present a leakage grading score in patients after esophagectomy including reconstruction with a gastric tube.

This new grading system needs to be tested in further analyses, with special focus on prospective analysis.

\section{Declarations}

Ethics approval and consent to participate: 
Every patient gave informed consent to present data in an anonymous form

Consent for publication:

Every author gave informed consent to publish the actual version of the manuscript

Availability of data and materials:

The underlying data of this retrospective analysis are saved in an anonymous matter in a data bank.

Competing interests:

None of the authors has a conflict of interest to declare.

Funding:

No sources of funding to declare.

\section{Authors' contributions:}

$\mathrm{JB}, \mathrm{MM}, \mathrm{MF}$ and HF developed the study design. JB collected the data and performed the data analysis including statistical analysis and drafted the manuscript. HF, MM, MF, MA and CS were involved in the critical revision of the manuscript for important intellectual content. Every author has read and approved the manuscript in its actual form.

\section{Acknowledgements:}

We would like to thank Editage (www.editage.com) for English language editing.

\section{References}

1. Jemal A, Bray F, Center MM, et al.: Global cancer statistics. CA Cancer J Clin 2011, 61(2):69-90.

2. Torre LA, Bray F, Siegel RL, et al.: Global cancer statistics, 2012. CA Cancer J Clin 2015, 65(2):87-108.

3. Alldinger I, Sisic L, Hochreiter M, et al.: Outcome, complications, and mortality of an intrathoracic anastomosis in esophageal cancer in patients without a preoperative selection with a risk score. Langenbecks Arch Surg 2015, 400(1):9-18.

4. Rasmussen SR, Nielsen RV, Fenger AS, et al.: Postoperative complications and survival after surgical resection of esophageal squamous cell carcinoma. J Thorac Dis 2018, 10(7):4052-4060.

5. Andreou A, Biebl M, Dadras M, et al.: Anastomotic leak predicts diminished long-term survival after resection for gastric and esophageal cancer. Surgery 2016, 160(1):191-203.

6. Booka E, Takeuchi H, Suda K, et al.: Meta-analysis of the impact of postoperative complications on survival after oesophagectomy for cancer. BJS Open 2018, 2(5):276-284. 
7. Goense L, van Rossum PS, Tromp M, et al.: Intraoperative and postoperative risk factors for anastomotic leakage and pneumonia after esophagectomy for cancer. Dis Esophagus 2017, 30(1):110.

8. Schniewind B, Schafmayer C, Voehrs G, et al.: Endoscopic endoluminal vacuum therapy is superior to other regimens in managing anastomotic leakage after esophagectomy: a comparative retrospective study. Surg Endosc 2013, 27(10):3883-3890.

9. Hagens ERC, Anderegg MCJ, van Berge Henegouwen MI, et al.: International Survey on the Management of Anastomotic Leakage After Esophageal Resection. Ann Thorac Surg 2018.

10. Wedemeyer J, Schneider A, Manns MP, et al.: Endoscopic vacuum-assisted closure of upper intestinal anastomotic leaks. Gastrointest Endosc 2008, 67(4):708-711.

11. Brangewitz M, Voigtlander T, Helfritz FA, et al.: Endoscopic closure of esophageal intrathoracic leaks: stent versus endoscopic vacuum-assisted closure, a retrospective analysis. Endoscopy 2013, 45(6):433-438.

12. Wedemeyer J, Brangewitz M, Kubicka S, et al.: Management of major postsurgical gastroesophageal intrathoracic leaks with an endoscopic vacuum-assisted closure system. Gastrointest Endosc 2010, 71(2):382-386.

13. Siewert JR, Stein HJ, Feith M: Surgical approach to invasive adenocarcinoma of the distal esophagus (Barrett's cancer). World J Surg 2003, 27(9):1058-1061.

\section{Figures}

Bachmann et al

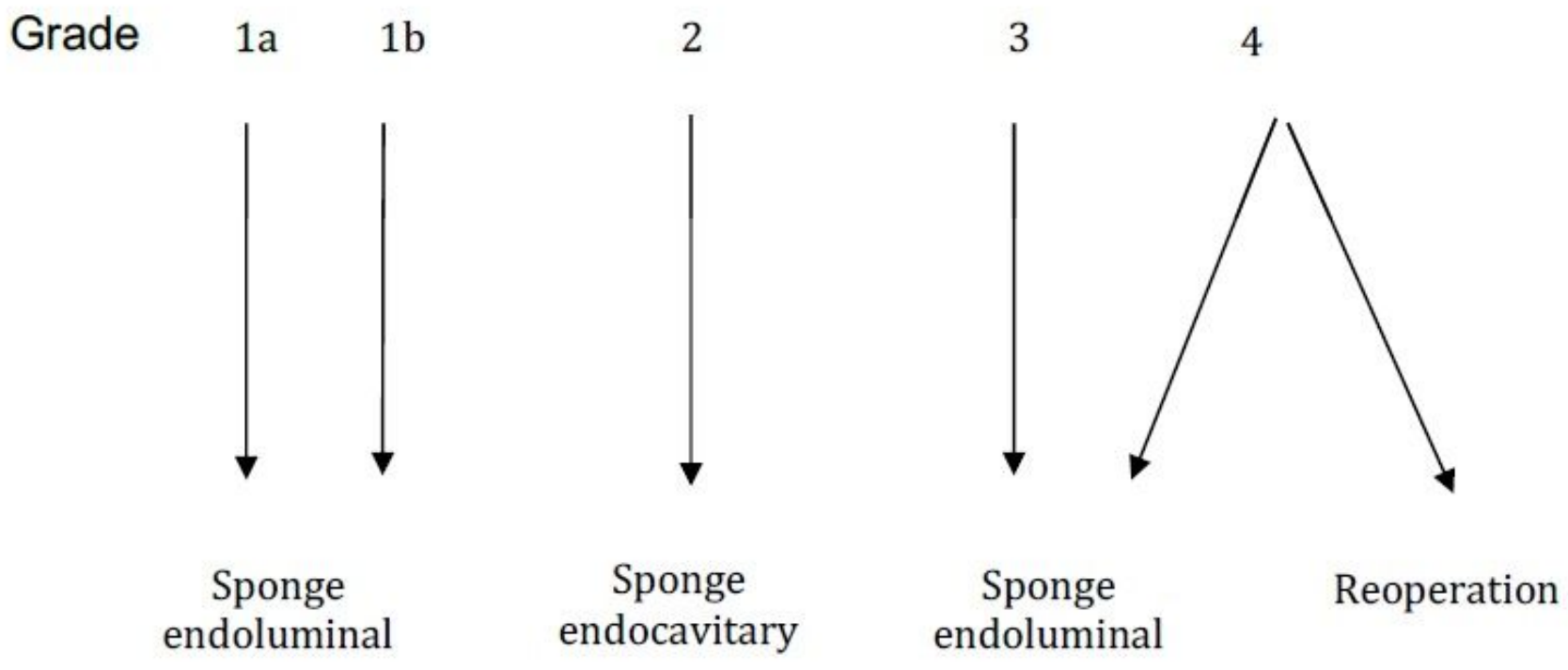

Figure 1 
Figure presents an algorithm that is used to determine where the sponge should be placed: in the lumen of the gastric tube or in the cavity. 